\section{Scrotal necrosis to total de-gloving injury of the male genitalia: an experience from Sub-Saharan Africa}

\author{
Christoph H. Houben, ${ }^{1}$ Chuks Azubuike, ${ }^{2}$ \\ Okogbe Ozoemena, ${ }^{2}$ Bala Saidu² \\ 'Department of Surgery, Prince of Wales \\ Hospital, The Chinese University of Hong \\ Kong, China; ${ }^{2}$ Yola Specialist Hospital, \\ Hospital Road, Yola, Nigeria
}

\section{Abstract}

Two patients with very different aetiologies of their genital injuries are presented: one lost his scrotal skin as a result of Fournier's gangrene, the other experienced complete denudation of scrotal and penile skin plus the amputation of his glans penis through an agricultural machinery. The placement of denuded gonads in thigh pouches and delayed skin grafting provide safe treatment options in a low budget setting of a Sub-Saharan country.

\section{Introduction}

We report our experience with two patients who sustained severe scrotal injuries in the low budget setting of a Sub-Saharan country. The injuries represent two ends of the spectrum of scrotal injuries: one patient lost his scrotum as the result of a severe infection to the perineum and scrotum (Fournier's gangrene), the other had a total de-gloving injury of his scrotum and penis plus avulsion of his glans penis through a mechanical devise. The management and treatment options of these very different aetiologies are outlined.

\section{Case Report \#1}

A seventy-year-old farmer was admitted to hospital for the first time in his life with generalised cardiac failure manifesting itself with shortness of breath and extensive oedema. He was commenced on diuretics and digitalized resulting in an improvement of his general condition, but during his hospitalisation he developed a sepsis causing Fournier's gangrene. Broad-spectrum antibiotics were given to control the synergistic infection typical of Fournier's gangrene. Aggressive debridement of the affected scrotal area was performed under general anaesthesia. This was followed by daily wound cleansing and dressing changes with vaseline gauze. There was a total loss of the scrotal skin with a significant absence of penile skin - the ventral defect being slightly larger than the dorsal defect. Both testes appeared denuded but with intact blood supply.

After around four weeks of daily dressing changes the wounds appeared clean for the reconstruction under general anaesthesia (Figure 1). During the operation the two testicles were placed in medial thigh pouches on the right and left side respectively and anchored with non-absorbable 3-0 Prolene ${ }^{\circledR}$ (Ethicon, Somerville, NJ, USA) sutures (Figures 2 and 3 ).

The remaining scrotal skin was closed and the penile shaft defect sutured. A week later some of the suture lines had broken down requiring partial re-suturing. The patient enjoyed normal micturition following the removal of his catheter after completion of the wound healing two weeks later.

\section{Case Report \#2}

A thirty-year-old, previously healthy farmer accidentally entangled his clothes with the belt of a grinding machine. The trapping of his scrotum in the grinder resulted in the total loss of his scrotum, penile skin and glans penis.

On arrival in the hospital the day after the injury, he had emergency surgery: on inspection there was a total loss of scrotal skin down to the perineum with the testicles exposed but viable, the penis was bleeding from its distal end as a result of complete loss of the glans penis in addition to the shaft- and foreskin loss. After catheterization, the extensively bleeding wound was sutured at the penile shaft and both testicles were securely placed in medial upper thigh pouches. In addition, a urethral fistula was repaired with 4-0 Monocryl ${ }^{\circledR}$ (Ethicon).

Postoperatively antibiotics and painrelief were continued; the vaseline dressing was changed daily. Twenty days following the accident a split skin graft was taken from his right thigh and the penile defect covered. Approximately $80 \%$ of the raw surface took the initial graft. The catheter was removed two weeks later. The patient made a good recovery and was discharged home with control of his urinary function and no penile discomfort. At this stage his erectile function was unclear.

\section{Discussion}

The mechanisms of scrotal injury range from incidents related to industrial and agricultural machinery, through animal attack to
Correspondence: Christoph Heinrich Houben, Department of Surgery, Prince of Wales Hospital, The Chinese University of Hong Kong, 7/F Clinical Sciences Building, Hong Kong, China. Tel. +86.852.26323936 - Fax: +86.852.26489384. E-mail: chhouben@web.de

Key words: Fournier's gangrene, genital trauma, de-gloving injury, Sub-Saharan Africa.

Contributions: $\mathrm{CH}$ operated on the patients, conceived the report and drafted the article; 00 assisted in the operations and contributed to the pre- and post-operative management of these patients; CA contributed to the pre- and postoperative management of the patients; and BS operated on one of the patients.

Conflict of interests: the authors declare no potential conflict of interests.

Acknowledgments: our patients have given permission to use their photographs in this article. Juliane Deubner, medical illustrator (Saskatoon, Canada) provided the graphics for Figure 3.

Received for publication: 3 February 2013.

Revision received: 15 May 2013.

Accepted for publication: 20 May 2013.

This work is licensed under a Creative Commons Attribution 3.0 License (by-nc 3.0).

(C) Copyright C.H. Houben et al., 2013

Licensee PAGEPress, Italy

Healthcare in Low-resource Settings 2013; 1:e16 doi:10.4081/hls.2013.e16

Fournier's gangrene. ${ }^{1}$

Overall total de-gloving injuries of the penis and scrotum are exceedingly rare. Large institutions manage only a handful of cases within a time span of a couple of decades. ${ }^{2}$ Loss of scrotal skin as a result of severe sepsis (Fournier's gangrene) is seen a little more frequently. ${ }^{3}$

Although Fournier is credited with the first description of necrotizing fasciitis in the perineum and scrotal region, gangrene was reported a century earlier. ${ }^{4}$

Fournier's gangrene is treated with broadspectrum antibiotics in an attempt to overcome the synergistic infection of gram-negative and gram-positive anaerobes and aerobes. Prompt debridement of the necrotic tissue as advocated initially by Meleney in the 1920 s has stood the test of time. ${ }^{5}$ Scrotal skin - supplied by branches of the pudendal artery - is often lost to variable degrees; the testicles receiving their blood supply directly from the aorta are rarely affected, as in our case. However, they may hang, bereft of cover, like the clappers of a bell (Figure 1). ${ }^{3}$

Once the wound is considered clean, the testicles may be placed in thigh pouches and 


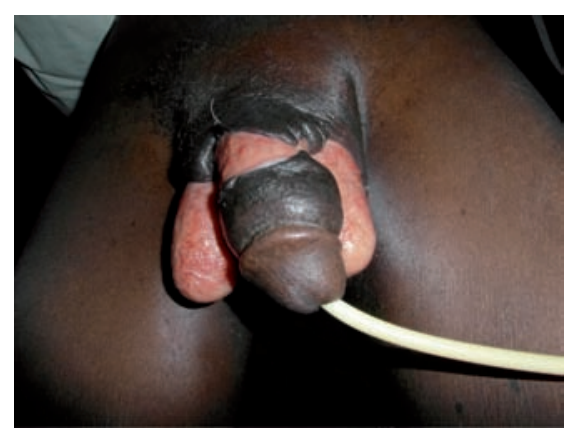

Figure 1. Scrotal and penile skin loss after Fournier's gangrene.

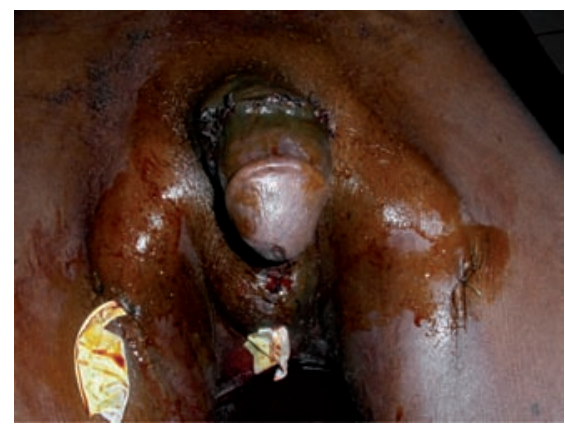

Figure 2. Post reconstructive surgery for scrotal skin loss secondary to Fournier's gangrene.

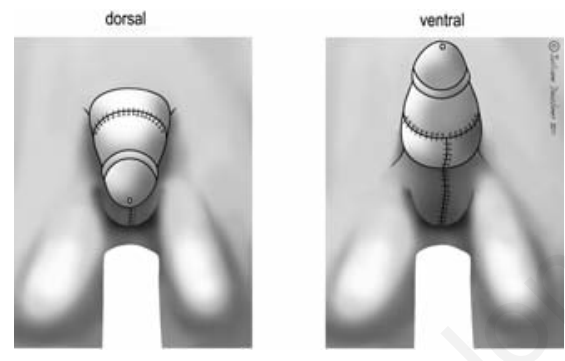

Figure 3. Graphic representation of the corrective surgery after scrotal loss due to Fournier's gangrene. the remaining wounds can be closed or if necessary covered with a split-skin-graft. At a later stage a new scrotum may be created using thigh pedicle flaps or meshed split-thickness grafts. ${ }^{1,6}$ Following consultation our patient did not wish to have further surgery done apart from the high risk of infection from further reconstructive surgery in a setting with very limited resources. In patients with $50 \%$ or less loss of scrotal skin secondary to a mechanical injury, a direct reconstruction should be possible. ${ }^{7}$ Total loss of the genital skin leaves the penile corpora most often intact;,2,8 our case was complicated by the amputation of the glans penis as a result of the accident.

In cases with total loss of genital skin secondary to trauma, one treatment option is to use thick-split-thickness or full-thickness grafts at the initial surgery with temporarily placement of the testes in thigh pouches. At a later stage, the creation of neo-scrotum is advocated. The alternative method is the direct reconstruction of the scrotum. ${ }^{1,2}$ If the avulsed scrotum is available, direct cover of the debrided wounds is naturally the preferred option. ${ }^{8}$

Although we appreciate the psychological advantage of immediate skin grafting and creation of a neo-scrotum, we delayed the application of a thick-split-skin graft for 18 days after the emergency surgery. The penile shaft wound was bleeding heavily and the risk of infection was deemed too high; in SubSaharan Africa wound infection rates of more than $30 \%$ are reported for injuries to the male external genitalia. ${ }^{9}$

Furthermore, we have currently no plans to create a new scrotum (e.g. tissue expansion) for the patient, because of the aforementioned risk of infection and the poor resources for equipment and materials in this low budget healthcare environment. Whilst this may be acceptable for the first patient who presented at an advanced age, the younger man has certainly a risk of low fertility. There is evidence that placement of testes in thigh pockets or reconstruction with thick skin flaps may impinge fertility in the long term. ${ }^{8}$

\section{Conclusions}

Despite our limited experience with de-gloving injuries of the scrotum in a low budget healthcare environment with a high infection risk - we had only two cases during a twelve months period - the following points can be made: i) preservation of denuded gonads is best achieved by creating thigh pouches; and ii) it is advocated to delay skin grafting of denuded penile areas.

\section{References}

1. McAninch JW. Management of genital skin loss. Urol Clin N Am 1989;16:387-97.

2. Finical SJ, Arnold PG. Care of the degloved penis and scrotum: a 25-year experience. Plast Reconstr Surg 1999;104:2074-8.

3. Eke N. Fournier's gangrene: a review of 1726 cases. Brit J Surg 2000;87:718-28.

4. Baurienne H. [Sur une plaie contuse qui s'est terminee par le sphacele de la scrotum]. [Article in French]. J Med Chir Pharm 1764;20:251-6.

5. Meleney FL. Hemolytic streptococcus gangrene. Arch Surg Chicago 1924;9:317-64.

6. Chen SY, Fu JP, Chen TM, Chen SG. Reconstruction of scrotal and perineal defects in Fournier's gangrene. J Plast Reconstr Aes 2011;64:528-34.

7. Selvan SS, Alagu GS, Gunasekraran R. Use of a hypogastric flap and split-thickness skin grafting for a degloving injury of the penis and scrotum: a different approach. Indian J Plast Surg 2009;42:258-60.

8. Wang D, Zheng H, Deng F. Spermatogenesis after scrotal reconstruction. Brit $\mathrm{J}$ Plast Surg 2003;56:484-8.

9. Ahmed A, Mbibu NH. Aetiology and management of injuries to male external genitalia in Nigeria. Injury 2008;39:128-33. 